\title{
Rat Lung Fibroblast Collagen Metabolism in Bleomycin-induced Pulmonary Fibrosis
}

\author{
Sem H. Phan, James Varani, and David Smith \\ Department of Pathology, University of Michigan Medical School, Ann Arbor, Michigan 48109
}

\begin{abstract}
Endotracheal bleomycin administration in rats and other animal species causes rapid development of pulmonary fibrosis, characterized by increased lung collagen synthesis and deposition. To clarify the mechanism, lung fibroblasts from bleomycintreated rats (BRF) were isolated and maintained in tissue culture. They were then compared with those from normal untreated control animals, with respect to several key parameters of collagen metabolism. BRF synthesized collagen at a rate $35-82 \%$ above normal rat lung fibroblasts (NRF). This difference did not appear to be due to the selection of a clone by the subculture process. Furthermore, analysis of newly synthesized collagen type composition, revealed a significantly lower ratio of type III to type I collagen. Noncollagenous protein synthesis, however, was not significantly different from normal. Collagenase production and growth rate were also unaffected. BRF, however, was morphologically indistinguishable from NRF, even at the ultrastructural level. Upon further bleomycin ( $1 \mu \mathrm{g} / \mathrm{ml}$ ) exposure in vitro, BRF could be further stimulated to synthesize collagen at $82 \%$ above the rate for untreated BRF. This is comparable to the $90 \%$ increase in NRF treated in vitro (compared with untreated NRF). These results would favor the conclusion that bleomycin induces pulmonary fibrosis, by causing directly and/or indirectly lung fibroblasts (or a certain line of lung fibroblasts) to synthesize collagen at a higher rate without any associated increase in growth rate. The data, however, do not rule out the possibility that the fibroblast isolation procedure has selected for a certain population of fibroblasts that may not be typical of the in vivo situation.
\end{abstract}

\section{Introduction}

Administration of the antitumor antibiotic bleomycin in humans and experimental animals, above certain cumulative doses, causes pneumonitis and pulmonary fibrosis $(1,2)$. The association between pneumonitis and fibrosis would suggest some role for cells of the inflammatory and immune systems and their mediators in regulating the fibrogenic response. There is ample evidence to support such a possibility in both bleomycin-induced, as well as, other forms of pulmonary fibrosis (3-6). A second possibility that products of alveolar

Dr. Phan is an established investigator with the American Heart Association.

Address correspondence to Dr. Phan.

Received for publication 1 December 1983 and in revised form 5 March 1985

J. Clin. Invest.

(C) The American Society for Clinical Investigation, Inc.

0021-9738/85/07/0241/07 \$1.00

Volume 76, July 1985, 241-247 epithelial, endothelial, and other cellular injury (as induced by bleomycin) are responsible for the accumulation of connective tissue has not been investigated. Finally, the fibrogenic response could also be the result of direct bleomycin stimulation of the lung connective tissue cells.

The ability of bleomycin to induce increased fibroblast net collagen synthesis in vitro has been demonstrated $(7,8)$. Further analysis reveals that most of the increased synthesis is in type I procollagen, resulting in a decreased ratio of newly synthesized type III to type I collagen (7). Polysomes from these bleomycin-treated cells synthesized more collagen than those from untreated control cells (8). Prolylhydroxylase activity is also increased, and is accompanied by increased rates of newly synthesized collagen degradation, as measured by quantitation of free and peptide-bound radioactive hydroxyproline (8). Other investigators have also reported that in vivo bleomycin treatment causes decreased collagenolytic activity in mouse skin (9) and rat lungs (10).

In this paper, the effect of in vivo bleomycin treatment on isolated rat lung fibroblasts was examined and compared with in vitro treatment. The data reveal some similarities, and suggest that bleomycin can cause pulmonary fibrosis, at least partially, by stimulation of lung fibroblast collagen synthesis due possibly to irreversible effects of certain cellular mediators.

\section{Methods}

Reagents. Outdated bleomycin (Blenoxane) was a generous gift of Bristol Laboratories Div., Bristol-Myers Co. (Syracuse, NY). L-[2,3,4,5${ }^{3} \mathrm{H}$ ]Proline $(>100 \mathrm{Ci} / \mathrm{mmol})$, [methyl ${ }^{3} \mathrm{H}$ ]thymidine $(6.7 \mathrm{Ci} / \mathrm{mmol})$, and [methyl- ${ }^{14} \mathrm{C}$ ]methylated collagen $(2-20 \mu \mathrm{Ci} / \mathrm{mg})$ were obtained from New England Nuclear (Boston, MA). Dulbecco's modified Eagle's medium (DME), ${ }^{1}$ penicillin-streptomycin-fungizone stock solution, and fetal calf serum were purchased from Gibco Laboratories (Grand Island, NY). Bacterial collagenase, CLSPA grade, was from Worthington Diagnostics Div. (Freehold, NJ). Trypsin (1:250) was from Difco Laboratories Inc. (Detroit, MI). Sodium ascorbate, ninhydrin, $N$ ethylmaleimide, and benzamidine $\mathrm{HCl}$ were from Sigma Chemical Co. (St. Louis, MO). $\beta$-Aminopropionitrile fumarate was from ICN Pharmaceuticals, Inc. (Cleveland, $\mathrm{OH}$ ). 4-Dimethylaminobenzaldehyde, acrylamide, and $N, N^{\prime}$-methylenebisacrylamide were from BDH Chemicals Ltd. (Poole, Dorset, England). EN ${ }^{3}$ HANCE and XAR-5 X-ray film were obtained from Eastman Kodak Co. (Rochester, NY). S-200 resin for gel filtration was from Pharmacia Fine Chemicals, Div. of Pharmacia Inc. (Piscataway, NJ), and DE52 anion exchange resin was purchased from Whatman Ltd. (Maidstone, Kent, England). All other chemicals were of analytical reagent grade, unless otherwise specified.

Animals. Male specific pathogen-free Fisher 344 rats weighing 200$250 \mathrm{~g}$ were obtained from Charles River Breeding Laboratories, Inc. (Wilmington, MA). These animals arrived in filtered cages, and were maintained in clean animal quarters separate from other laboratory

1. Abbreviations used in this paper: BRF, fibroblasts obtained from lungs of bleomycin-treated rats; DME, Dulbecco's modified Eagle's medium; NRF, normal rat lung fibroblasts; PAGE, polyacrylamide gel electrophoresis; PMSF, phenylmethylsulfonylfluoride. 
animals. Pulmonary fibrosis was induced by the endotracheal injection of $1.5 \mathrm{U}$ (in $300 \mu \mathrm{l}$ of sterile saline) bleomycin by tracheostomy as described previously $(3,10)$. Control animals received the same volume of sterile saline only.

Lung fibroblast isolation. Animals treated as above were killed at $14 \mathrm{~d}$ after bleomycin instillation by exsanguination under ketamine anesthesia (10). Using sterile techniques the lungs were then perfused with sterile phosphate-buffered saline (PBS) via the right ventricle until they were pale. The lungs were then removed using sterile instruments and trimmed of extraneous tissues, bronchial, and vascular structures. After mincing to 2-4-mm pieces, they were suspended in sterile PBS containing $0.5 \%$ trypsin and incubated with gentle stirring at $37^{\circ} \mathrm{C}$ for 20-35 min. Dispersed cells were then collected and separated from undigested tissue and debris by filtration through sterile gauze. Cells were then washed once with PBS, once with DME containing 10\% fetal calf serum, and finally resuspended in this media. They were then incubated in a $\mathrm{CO}_{2}(5 \%)$ incubator at $37^{\circ} \mathrm{C}$. After $24-48 \mathrm{~h}$, unattached cells were removed by washing, and fresh media added. After another 24-48 $\mathrm{h}$, the tissue culture flasks were usually confluent, and the cells were passaged by detaching with $0.25 \%$ trypsin in PBS (3-5 min at $37^{\circ} \mathrm{C}$ ) and splitting the cells $1: 3$. Cells were then maintained in DME containing $10 \%$ fetal calf serum and passaged every 3-5 d. By the fourth passage, the cells formed homogeneous monolayers morphologically consistent with fibroblast-like cells, as examined under phasecontrast light microscopy. All experiments were undertaken only with cells between the 4th and 15 th passages. No morphologic or functional (as assayed below) abnormalities were observed during these passages. Growth rate was noted to decrease significantly beyond the 25th passage.

Electron microscopy. For electron microscopy, fibroblasts were trypsinized, washed, and centrifuged to form a pellet. The cells were then fixed in suspension by adding an equal volume of $4 \%$ glutaraldehyde (Polysciences Inc., Warrington, PA) in $0.1 \mathrm{M} \mathrm{Na}$ cacodylate buffer, $\mathrm{pH} 7.2$, for $1 \mathrm{~h}$ at $4^{\circ} \mathrm{C}$. The cells were spun down to a pellet and washed in $0.1 \mathrm{M} \mathrm{Na}$ cacodylate buffer twice. The pellet was resuspended and postfixed with $2 \%$ osmium tetroxide (Electron Microscopy Sciences, Fort Washington, PA) in $0.1 \mathrm{M} \mathrm{Na}$ cacodylate buffer, pH 7.2, for $1 \mathrm{~h}$ at $4^{\circ} \mathrm{C}$. The cell suspension was then spun down to a pellet, washed with $0.1 \mathrm{M}$ cacodylate buffer, $\mathrm{pH} 7.2$, dehydrated with graded alcohol solutions, infiltrated with propylene oxide-epon mixtures, and embedded in epon 812 (Electron Microscopy Sciences). Ultrathin sections were mounted on copper grids and stained with a saturated solution of aqueous uranylacetate for $1 \mathrm{~h}$ at $25^{\circ} \mathrm{C}$ followed by lead citrate solutions for $5 \mathrm{~min}$. Thin sections were examined with a Philips EM 400T (Philips Electronic Instruments, Inc., Mahwah, NJ).

Measurements of growth rate. Fibroblast proliferation was measured by two methods. The first involved measuring the rate of cellular $\left[{ }^{3} \mathrm{H}\right]$ methylthymidine uptake into DNA. Fibroblasts were suspended in DME after detachment by brief trypsinization. $10^{4}$ Cells were then placed in each well of a microtiter plate (Costar, Data Packaging Corp., Cambridge, MA) in $200 \mu$ l of DME containing $10 \%$ fetal calf serum. The cells were then pulsed for $6 \mathrm{~h}$ by addition of $10 \mu \mathrm{l}$ DME containing $1 \mu \mathrm{Ci}$ of $\left[{ }^{3} \mathrm{H}\right]$ methylthymidine. At the end of the pulse, the cells were harvested using $0.25 \%$ trypsin and transferred to glass fiber filters using an automatic cell harvester (Bellco Glass, Inc., Vineland, $\mathrm{NJ}$ ). After they were washed with cold 5\% trichloracetic acid (TCA) and distilled $\mathrm{H}_{2} \mathrm{O}$, the filters were dried, placed in vials, and counted in a scintillation counter (model LS7000; Beckman Instruments, Inc., Fullerton, CA). The results were expressed as disintegrations per minute incorporated per $6 \mathrm{~h} /$ well.

Actual growth curves were also obtained to measure proliferation. Fibroblasts were plated onto $35-\mathrm{mm}$ diameter tissue culture dishes in DME supplemented with $10 \%$ fetal calf serum (Costar, Data Packaging Corp.). At daily intervals, up to $5 \mathrm{~d}$ after plating, the dishes were trypsinized $(0.25 \%$ trypsin) to detach the cells, which were placed in hemocytometers for actual cell counting using the microscope. Results were expressed as cell number per dish.

Collagen production. Collagen synthesis (net production) assays were performed using only fully confluent cells in 35-mm diameter tissue culture dishes. Spent media were removed and the monolayer was washed twice gently using DME (prewarmed to $37^{\circ} \mathrm{C}$ ). Cells to be treated with bleomycin in vitro were then incubated for $24 \mathrm{~h}$ in DME containing the desired concentration of drug. Cells were then pulsed by replacing the media with fresh DME supplemented with $50 \mu \mathrm{g} / \mathrm{ml}$ sodium ascorbate, $80 \mu \mathrm{g} / \mathrm{ml} \beta$-aminopropionitrile, and $10 \mu \mathrm{Ci} / \mathrm{ml}$ $\left[{ }^{3} \mathrm{H}\right]$ proline. After a 6-h incubation with $5 \% \mathrm{CO}_{2}$ and at $37^{\circ} \mathrm{C}$, the media and one wash $(1.0 \mathrm{ml}$ of PBS) were separated from the cell layer. The latter was scraped using a rubber policeman and resuspended in $2.0 \mathrm{ml}$ PBS. Both media (after supplementation with $0.2 \mathrm{mg} / \mathrm{ml}$ with bovine serum albumin) and cell layer samples were then made up to $10 \%$ in TCA using a $50 \%$ stock solution. The pellets after centrifugation were washed twice with cold $10 \%$ TCA and finally resuspended in $500 \mu \mathrm{l} 0.1 \mathrm{~N} \mathrm{NaOH}$. After a 10-min incubation at $37^{\circ} \mathrm{C}$, the suspension was neutralized to $\mathrm{pH} 7.3-7.5$ with $1.0 \mathrm{~N} \mathrm{HCl}$ after addition of $250 \mu \mathrm{l}$ of $1.0 \mathrm{M}$ Tris $\mathrm{HCl}, \mathrm{pH}$ 7.5. The final volume was then made up to $1.0 \mathrm{ml}$ using distilled $\mathrm{H}_{2} \mathrm{O}$. A $100-\mu \mathrm{l}$ aliquot of the cell layer was then taken for protein determination. The samples were then supplemented with (in final concentrations) $5 \mathrm{mM} \mathrm{N}$ ethylmaleimide, $10 \mathrm{mM}$ benzamidine, $0.2 \mathrm{mM}$ phenylmethylsulfonylfluoride (PMSF), and $5 \mathrm{mM} \mathrm{CaCl}_{2}$. 500- $\mu$ l samples were then digested for $2 \mathrm{~h}$ at $37^{\circ} \mathrm{C}$ with $35 \mu \mathrm{g}$ of bacterial collagenase, previously purified by gel filtration on Sephacryl S-200 resin $(10,11)$. Previous data (10) and other control studies (not shown) have demonstrated that no more radioactivity was digested beyond $60-90 \mathrm{~min}$ of incubation. The digests were then processed exactly as described previously (10), which is a minor modification of the method of Peterkovsky and Diegelmann (11). Collagenase-digestible counts were empirically defined as collagenous synthesis, while the collagenase-resistant counts were referred to as noncollagenous protein synthesis. Results were expressed as disintegrations per minute incorporated per milligram of cell protein. No significant differences were noted when data were expressed as per $10^{5}$ cells as determined by cell counting using the hemocytometer. No correction was attempted for variation in intracellular proline pool size, since no significant difference in proline pool size was detected between normal rat lung fibroblasts (NRF) and fibroblasts obtained from lungs of bleomycin-treated rats (BRF) (see Results). Using this method, the rate of incorporation was linear up to at least $24 \mathrm{~h}$ of pulsing.

Characterization and quantitation of collagen type ratios. The newly synthesized collagens were characterized and quantitated with respect to their type III vs. type I ratio using two different methods. The first method is based on the ability of anion exchange chromatography to separate procollagens type I from type III (7). For these studies, cells grown to confluence in three $75-\mathrm{mm}^{2}$ flasks $(\mathrm{T}-75)$ were pulsed as described above with $5.0 \mu \mathrm{Ci} / \mathrm{ml}\left[{ }^{14} \mathrm{C}\right]$ proline for $60 \mathrm{~h}$. The media were then harvested, pooled, and immediately put on ice. The following were then added (in final concentrations): $0.5 \mathrm{mM}$ PMSF, $5 \mathrm{mM}$ EDTA, and $2.5 \mathrm{mM} N$-ethylmaleimide. The procollagens were then precipitated with $\left(\mathrm{NH}_{4}\right)_{2} \mathrm{SO}_{4}$ at $20 \%$ saturation at $4^{\circ} \mathrm{C}$ for $18 \mathrm{~h}$ (7). After centrifugation at $48,000 \mathrm{~g}$ for $30 \mathrm{~min}$, the pellet was resuspended in start buffer composed of $25 \mathrm{mM}$ Tris $\mathrm{HCl}, \mathrm{pH} 7.5,1$ $\mathrm{mM}$ EDTA, and $2 \mathrm{M}$ urea. After exhaustive dialysis against this buffer, the preparation was applied on a column $(2.5 \times 10 \mathrm{~cm})$ of DE52. The chromatogram was developed according to Clark et al. (7), and 2-ml fractions were collected and counted with an efficiency of $>75 \%$. Selected fractions were also assayed for radioactive hydroxyproline after acid hydrolysis, according to the method of Juva and Prockop (12), with slight modifications (13).

The second method was based on separation of collagen types by polyacrylamide gel electrophoresis (PAGE) in the presence of sodium dodecyl sulfate (SDS) with interrupted reduction (14). The samples were prepared as for ion-exchange chromatography, but the $20 \%$ saturated $\left(\mathrm{NH}_{4}\right)_{2} \mathrm{SO}_{4}$ pellet was pepsin-digested (7) before resuspension in dissociation medium composed of $20 \mathrm{mM}$ Tris $\mathrm{HCl}, \mathrm{pH} 6.8,2 \%$ SDS, and $10 \%$ glycerol. After they were heated in a boiling water bath for $2 \mathrm{~min}$, the samples were allowed to cool before application to the 
gel. The SDS-PAGE was run as a slab according to Neville (15) with slight modifications (16). The acrylamide concentration was $8 \%$ with $0.22 \% N, N^{\prime}$-methylenebisacrylamide as cross-linker. After running for $30 \mathrm{~min}$, the current was interrupted and $10 \mu \mathrm{l}$ of mercaptoethanol was added per well to dissociate the type III collagen into their $\alpha_{1}$-subunits (14). At the end of the run, and upon fixing, staining, impregnating with EN ${ }^{3} \mathrm{HANCE}$, and drying, the gels were exposed to XAR-5 film for 2-5 $\mathrm{d}$ before development using a standard commercial X-ray film developer. The autoradiograms were then scanned and bands quantitated using a Zeineh laser densitometer (LKB Instruments, Gaithersburg, MD) equipped with an integrator.

Collagenase assay. Collagenase production and/or release were measured by assaying the conditioned media of the cultured lung fibroblasts for total (i.e., latent plus active) collagenase activity. Media from seven T-25 flasks were pooled and concentrated 10-15-fold using an Amicon device and a UM10 membrane (Amicon Corp., Scientific Sys. Div., Danvers, MA) at $4^{\circ} \mathrm{C}$. Since latent activity was very low, only total activity was determined by predigesting the concentrated conditioned media with $10 \mu \mathrm{g} / \mathrm{ml}$ of trypsin for $15 \mathrm{~min}$ at $37^{\circ} \mathrm{C}$. The trypsin was then inactivated with $40 \mu \mathrm{g} / \mathrm{ml}$ of soybean trypsin inhibitor. $160-\mu l$ aliquots of the concentrated media were then incubated with $100 \mu \mathrm{l}$ of substrate solution containing $0.2 \mu \mathrm{Ci} / \mathrm{ml}$ of ${ }^{14} \mathrm{C}$-methylated acid soluble calf skin collagen, $10 \mu \mathrm{g} / \mathrm{ml}$ cold acid soluble calf skin collagen, $50 \mathrm{mM}$ Tris $\mathrm{HCl}, \mathrm{pH} 7.5,0.2 \mathrm{M} \mathrm{NaCl}, 5 \mathrm{mM} \mathrm{CaCl}_{2}, 5 \mathrm{mM}$
$N$-ethylmaleimide, $10 \mathrm{mM}$ benzamidine, and $0.2 \mathrm{mM}$ PMSF. After an 18-h incubation at $25^{\circ} \mathrm{C}, 100 \mu \mathrm{l}$ of a solution containing $60 \mathrm{mM}$ Tris $\mathrm{HCl}, \mathrm{pH} 6.8,3 \%$ SDS, $20 \%$ glycerol, and $10 \%$ mercaptoethanol was added and the samples were heated in a boiling water bath for $2 \mathrm{~min}$. $100 \mu l$ was then subjected to SDS-PAGE as described above and the radioactive bands were quantitated by integration of a densitometric scan of the autoradiogram. Results were expressed as percentage of total radioactivity (in all bands) in the $\mathrm{TC}_{\mathrm{A}}$ and $\mathrm{TC}_{\mathrm{B}}$ bands.

\section{Results}

Fibroblast isolation. Addition of collagenase to lung mince did not improve the yield of fibroblasts significantly, and thus collagenase was omitted. Lung tissue from bleomycin-treated animals was more efficiently digested than normal lungs. Thus less incubation time was required for bleomycin lungs to achieve the same cellular yield as from control lungs. This is probably the result of increased cellularity in bleomycin lungs due to influx of inflammatory cells and increased connective tissue cells. No morphologic differences were apparent between NRF and BRF, using both phase-contrast light microscopy and electron microscopy. Electron microscopy of NRF and BRF (Figs. $1 A$ and $B$ ) revealed characteristic fibroblast features

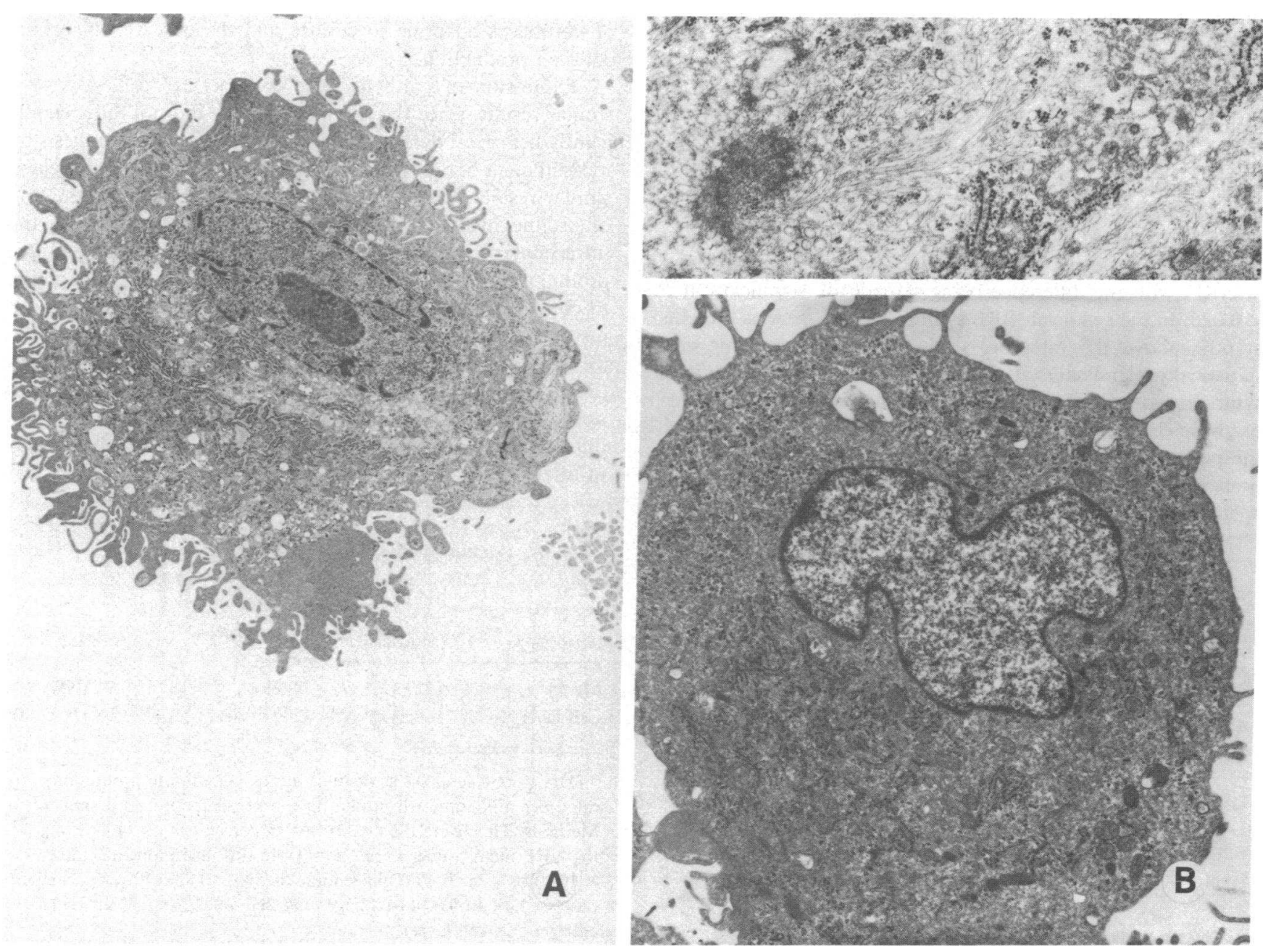

Figure 1. Electron micrographs of $(A) \mathrm{NRF}$ and $(B)$ BRF. Cells were prepared, fixed, and subjected to microscopy as described in Methods. $(A)$

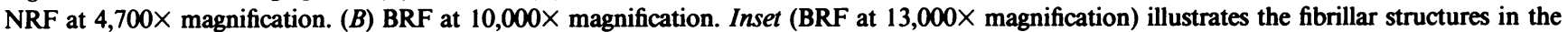
cytosol. 
with relatively smooth nuclear outlines and extensive rough endoplasmic reticulum suggestive of active protein synthesis. Elongated projections representative of anchoring strands were also present. Although fine fibrillar structures (Fig. $1 \mathrm{~B}$, inset) were present in the cytosol (of both NRF and BRF), the more massive bundles of filament containing electron-dense areas, typical of myofibroblasts (17), were not seen. Thus from the morphologic standpoint, no differences were apparent between NRF and BRF.

Growth rate. Increased connective tissue deposition may be a result of increased fibroblast metabolic activity and/or proliferation. Using the fibroblast isolation procedure as described above, and in vitro measurements of cell growth, no detectable difference was noted between NRF and BRF growth rates (Fig. 2). Using cell-counting techniques, a doubling time of just under $2 \mathrm{~d}$ was obtained for both NRF and BRF. DNA synthetic rates were also unchanged as a result of in vivo bleomycin treatment. NRF incorporated 6,750 271 (SEM) $\mathrm{dpm} /$ well $(n=6)$, and BRF incorporated 6,393 0300 (SEM) $\mathrm{dpm} /$ well $(n=6)$ of $\left[{ }^{3} \mathrm{H}\right]$ methylthymidine in $6 \mathrm{~h}$ of incubation. These data suggest that bleomycin treatment in vivo caused no significant change in lung fibroblast growth rates, at least after isolation for in vitro measurements. Doubling times as well as DNA synthetic rates were also unchanged as a function of the number of passages the cells underwent (Table I). This implies that at least according to this parameter of cell function, no clonal selection took place to account for the observed differences (in collagen production) in later passages.

Collagen production. Bleomycin-induced pulmonary fibrosis is characterized by increased lung collagen accumulation (13). Other investigators have also reported on the ability of bleomycin to directly stimulate fibroblast collagen production in vitro $(7,8)$. Similar results were obtained from BRF. Table II shows the results of a typical experiment with BRF synthesizing collagen and secreting into the media at a rate $52 \%$ above that of NRF, with the difference being statistically significant at $P$ $<0.025$. In the cell layer, BRF synthesized collagenous proteins at $60 \%$ above the rate for NRF, the difference being also statistically significant at $P<0.02$. Noncollagenous protein synthetic rates, however, were unaffected in the media layer, but were elevated by $47 \%(P<0.05)$ in the cell layer. Although the percent increase above NRF was variable from one BRF preparation to another, every preparation tested demonstrated a statistically significant increase, with a range of $35-82 \%$

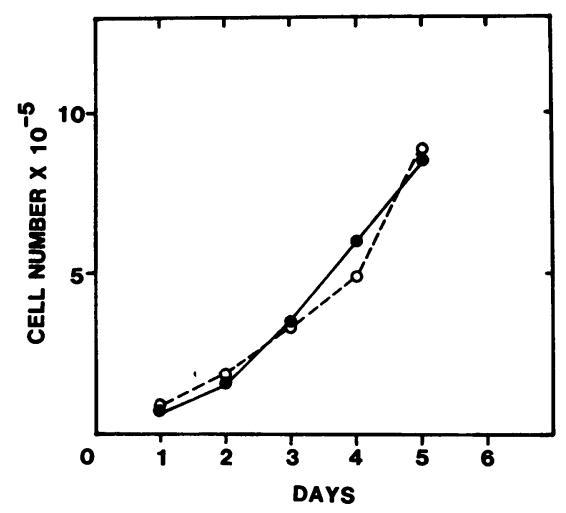

Figure 2. Comparison of growth rates. Solid circles represent NRF while open circles represent BRF. Data were expressed as the total cell count in a tissue culture dish as a function of time after plating, as described in detail in Methods.
Table I. Effect of Passage Number on Cell Growth

\begin{tabular}{llll}
\hline $\begin{array}{l}\text { Cell } \\
\text { type }\end{array}$ & $\begin{array}{l}\text { Passage } \\
\text { number }\end{array}$ & $\begin{array}{l}\text { Doubling } \\
\text { time }\end{array}$ & $\begin{array}{l}\text { DNA } \\
\text { synthesis* }\end{array}$ \\
\hline & & $h$ & $d p m$ \\
NRF & 1 (Primary) & $52 \pm 3.5$ & $5,977 \pm 629$ \\
& 2 & $49 \pm 4.3$ & $6,237 \pm 798$ \\
& 5 & $46 \pm 6.1$ & $6,711 \pm 723$ \\
& 10 & $50 \pm 6.0$ & $6,033 \pm 811$ \\
BRF & 1 (Primary) & $58 \pm 6.2$ & $5,799 \pm 701$ \\
& 2 & $50 \pm 6.9$ & $6,022 \pm 893$ \\
& 5 & $51 \pm 6.0$ & $6,735 \pm 877$ \\
& 10 & $48 \pm 5.9$ & $6,230 \pm 739$ \\
& & &
\end{tabular}

Data are expressed as means of triplicate determinations \pm SE. * DNA synthesis was defined by $\left[{ }^{3} \mathrm{H}\right]$ thymidine (in disintegrations per minute) uptake (in $6 \mathrm{~h}$ ) per microtiter well as described in Methods.

above the rate for NRF. Additionally this increased synthesis was specific for collagenous protein, especially in terms of secreted proteins. The basis for this variability is uncertain but may be related to the variability in response to the outdated bleomycin. There is no relationship between the initial number of fibroblasts adapting to culture and the observed increased collagen production.

Expression of synthetic rates on a per $10^{5}$ cell basis gave similar results, since the protein/cell ratio did not differ significantly between NRF and BRF. Determination of synthesis by measurement of radioactive hydroxyproline $(12,13)$ also yielded similar results (data not shown). The possibility that the rate of proline incorporation may be altered by changes in the intracellular pools was investigated by measuring total free proline in both BRF and NRF. This was done on cells grown to confluence and incubated $6 \mathrm{~h}$ in fresh serum-free medium just before assay. The results show NRF to contain $38.03 \pm 1.93$ (SEM, $n=4)$ nmol free proline/mg protein vs. $35.07 \pm 2.11$ $(\mathrm{SEM}, n=4) \mathrm{nmol} / \mathrm{mg}$ protein in BRF. The difference was not statistically significant, thus making it unlikely that any difference in rates of proline incorporation was due to changes in total proline pool size.

Table II. Protein Synthesis in BRF

\begin{tabular}{lll}
\hline & Protein synthetic rates* \\
\cline { 2 - 3 } Incorporation & Collagenous $¥$ & Noncollagenous \\
\hline Media & $152 \pm 12.5(P<0.025) \S$ & $113 \pm 9.9 \quad(\mathrm{NS})$ \\
Cell layer & $160 \pm 11.7(P<0.02)$ & $147 \pm 12.8(P<0.05)$
\end{tabular}

* Data were calculated as disintegrations per minute proline incorporated per milligram cell protein in $6 \mathrm{~h}$ of incubation as described in Methods. They were then expressed as percentage of the corresponding NRF mean values ( $\pm \mathrm{SE}, n=3$ ) (in disintegrations per minute $\times 10^{-5}$ ) of $7.28 \pm 0.45$ (collagenous, media), 10.8 \pm 0.70 (noncollagenous, media), $1.69 \pm 0.11$ (collagenous, cell layer), and 12.9 \pm 2.3 (noncollagenous, cell layer).

¥ This was distinguished according to susceptibility to purified bacterial collagenase digestion as described in Methods.

$\S$ These values were determined using the two-tailed unpaired $t$ test, comparing BRF vs. NRF values. 
Table III. Effects of Passaging on BRF Protein Synthesis*

\begin{tabular}{|c|c|c|}
\hline \multirow{2}{*}{$\begin{array}{l}\text { Passage } \\
\text { number }\end{array}$} & \multicolumn{2}{|c|}{ Protein synthesis } \\
\hline & Totalł & Percent collagenous \\
\hline 1 (Primary) & $160 \pm 9.5$ & $114 \pm 3.9$ \\
\hline 3 & $155 \pm 7.3$ & $126 \pm 4.8$ \\
\hline 7 & $163 \pm 9.7$ & $122 \pm 5.8$ \\
\hline 10 & $159 \pm 2.9$ & $118 \pm 4.3$ \\
\hline
\end{tabular}

* Data are expressed as means of triplicate determination \pm SE. All values refer to products secreted into the media.

¥ This refers to total $\left[{ }^{3} \mathrm{H}\right]$ proline incorporated to TCA insoluble material and expressed as percentage of corresponding NRF mean value. $\S$ This refers to percentage of TCA soluble material digestible by purified collagenase as calculated using the following formula to correct for the relative abundance of proline in collagenous proteins: \% $\mathrm{C}$ $=(\mathrm{C}) /[\mathrm{C}+5.04(\mathrm{NC})] \times 100 \%$, wherein $\mathrm{C}=$ disintegrations per minute digestible by collagenase and $\mathrm{NC}=$ disintegrations per minute not susceptible to collagenase digestion. The data are expressed as percentage of corresponding NRF mean value.

To conclusively confirm this increased synthesis, cells were maintained for $24 \mathrm{~h}$ in serum-free media containing $50 \mu \mathrm{g} / \mathrm{ml}$ ascorbic acid and $80 \mu \mathrm{g} / \mathrm{ml} \beta$-aminopropionitrile. The media from five T-75 flasks were then pooled and assayed for total hydroxyproline content (10). The results from one preparation showed $200 \pm 24$ (SEM, $n=4$ ) $\mu$ g collagen/flask for NRF vs. $382 \pm 41$ (SEM, $n=5$ ) for BRF. This difference was statistically significant at $P<0.02$, thus conclusively confirming the results of the radiotracer experiments.

To ascertain that this increase in collagen production by BRF was not due to selection of a more active clone by the passaging process, experiments were undertaken to examine the effect of passaging on the observed differences in this parameter. Table III revealed that increased collagen production was relatively invariant as a function of passage number (from the primary to tenth passage). The results again suggest that the observed difference between NRF and BRF is not due to clonal selection by the process of subculture.

Type III/type I ratios. Fibrotic lesions are known to contain lesser amounts of type III collagen relative to type I collagen (18-20), except in the early stages of wound healing (21). Bleomycin treatment, in vivo causes a similar decrease in the relative type III collagen content of lungs (22). In vitro treatment of isolated fibroblasts by this drug also results in a reduction in this ratio (type III vs. type I) in the newly synthesized procollagens (7). Figs. 3 and 4, and Table IV show that BRF also synthesized collagens with a lower type III/

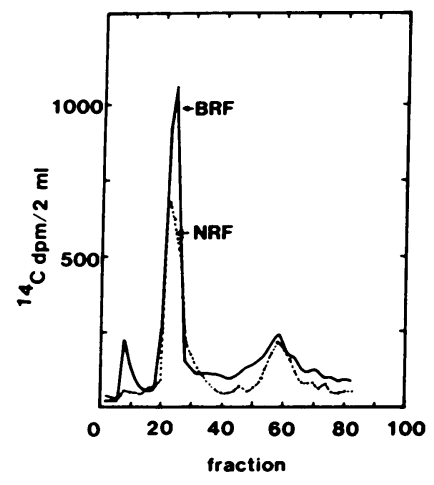

Figure 3. Quantitation of procollagen types III/I ratios by anion exchange chromatography. Separation was achieved using a DE52 column and elution with a linear gradient of $0.0-0.22 \mathrm{M} \mathrm{NaCl}$ following a 25-ml wash with the start buffer as described in Methods. 2.0-ml fractions were collected and counted.

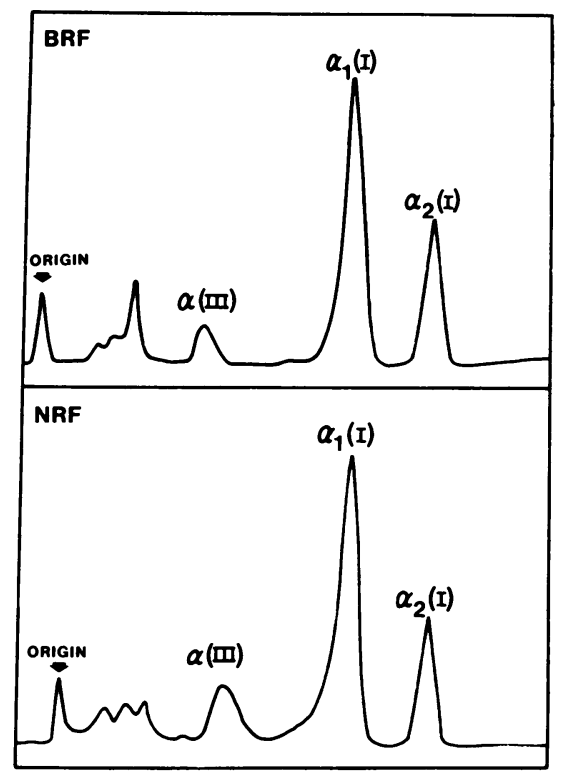

Figure 4. Quantitation of collagen types III/I ratios by gel electrophoresis. Top of the gel is on the left. The ordinate represents relative absorbance of a 633-nm laser beam, and the abscissa is relative gel distance.

type I collagen ratio. Analysis by anion-exchange chromatography revealed BRF to synthesize only $60 \%$ of the relative content of type III procollagen synthesized by NRF (Fig. 3). Analysis by SDS-PAGE revealed a comparable reduction of $58.4 \%$ by BRF relative to NRF (Fig. 4). These differences between NRF and BRF values were statistically significant at $P<0.05$.

Collagenase production. Previous studies using a cutaneous model of bleomycin-induced fibrosis revealed a reduction in skin collagenase activity (9). Such a reduction in collagen catabolism has been suggested as a contributor to the fibrotic end result (10). Although there is also an overall reduction in total lung collagenolytic activity after bleomycin treatment (10), BRF-conditioned media revealed similar levels of total collagenase activity as NRF media $(17.6 \pm 1.9 \%$ digestion for BRF vs. $18.7 \pm 1.3 \%$ for NRF; values were mean \pm SEM, $n$ $=4$ ). Thus, increased collagen synthesis in BRF cannot be attributed to decreased collagenase secretion and activity.

Effects of in vitro bleomycin. In vitro bleomycin treatment

Table IV. Comparison of Relative Content of Type III Collagen Synthesized

\begin{tabular}{llc}
\hline & Percent type III procollagen* & Percent type III collagen¥ \\
\hline NRF & $22.5 \pm 2.1(100 \%)$ & $15.4 \pm 1.1(100 \%)$ \\
BRF & $13.5 \pm 1.5(60 \%)$ & $9.0 \pm 0.9(58.4 \%)$
\end{tabular}

* Determined by ion-exchange chromatography on DE52 as described in Methods and expressed as percent radioactive hydroxyproline in type III procollagen peak relative to total radioactivity in both types I and III peaks. All data are expressed as mean \pm SE of three different gel runs.

¥ Determined by SDS-PAGE with interrupted reduction of pepsin digested procollagens as described in Methods. Data (mean $\pm \mathrm{SE}, n=3$ ) are expressed as percentage of integration units in the type III collagen band vs. total units in type III, $\alpha_{1}$ (I), and $\alpha_{2}$ (I) collagen bands. 
is known to cause increased collagen synthesis in isolated normal fibroblasts or fibroblast cell lines $(7,8)$. Similar treatment of BRF caused a further stimulation of collagen synthesis above untreated BRF (Table V). $1.0 \mu \mathrm{g} / \mathrm{ml}$ of bleomycin stimulated BRF and NRF 82 and $90 \%$, respectively, above their respective untreated controls. A higher dose of bleomycin $(5.0 \mu \mathrm{g} / \mathrm{ml})$ was not as stimulatory because of cytotoxicity, as indicated by the increased numbers of cells incapable of excluding trypan blue. Thus BRF could be further stimulated by additional in vitro bleomycin treatment to an extent comparable to NRF, which has not been previously exposed to this drug.

\section{Discussion}

A major toxic side effect during chemotherapy with bleomycin is cutaneous and pulmonary fibrosis $(1,2)$. Although the cellular toxicity and ability of this drug to cause DNA strand scission in vitro has been well studied, the actual mechanism of in vivo toxicity resulting in pulmonary fibrosis is much less clear. Earlier studies have revealed the importance of the host's immune system $(4,10)$ and serum complement $(3,23)$ in regulating complete expression of the fibrogenic response to bleomycin. In this study, lung fibroblasts were isolated from normal and bleomycin-treated rats and characterized with respect to several parameters relevant to the fibrogenic process, in an attempt to examine for any detectable in vitro change as a consequence of the totality of the in vivo response to bleomycin. Since maximal increase in lung collagen synthesis is noted at $\sim 14 \mathrm{~d}$ after bleomycin treatment, BRF was obtained at this time point.

The results show that BRF produced collagen at a significantly higher rate than NRF, unaccompanied by any alteration in growth rate. The lack of significant difference in growth rate is in contrast to a recent study (24) using a similar model but different time points (7-8 d after bleomycin instillation vs. $14 \mathrm{~d}$ in this study) and method for lung fibroblast isolation (outgrowths from lung explants vs. trypsin digestion in this study). The discrepancy may be the result of one or both of these two factors. However, in their system, isolation using proteases also yielded the same result (Absher, M., J. Hildebran, L. Trombley, J. Woodcock-Mitchell, and J. Marsch, unpublished observations) (24), thus suggesting that the difference in time of isolation after bleomycin instillation may be the critical factor. This possibility is consistent with the following scenario. Initial direct bleomycin toxicity impairs the growth and proliferation of lung cells, including fibroblasts. Recovery from

Table V. Effects of In Vitro Bleomycin Treatment on Isolated Lung Fibroblast Collagen Production

\begin{tabular}{llc}
\hline Cells & Treatment & Collagen production* \\
\hline & $\mu g /$ ml bleomycin & $d p m \times 10^{-5} /$ mg cell protein $^{*}$ \\
NRF & 0.0 & $6.84 \pm 0.39$ \\
NRF & 1.0 & $13.02 \pm 0.75$ \\
NRF & 5.0 & $9.46 \pm 0.46$ \\
BRF & 0.0 & $10.36 \pm 0.86$ \\
BRF & 1.0 & $18.91 \pm 1.49$ \\
BRF & 5.0 & $12.01 \pm 1.25$
\end{tabular}

* Values represent mean $\pm \operatorname{SE}(n=3)$. Collagen production is measured as described in Methods. this insult begins to occur during the second week, which is associated with the fibrogenic response. This recovery may involve the recruitment of and/or the selection for a different fibroblast population with either a normal or possibly an increased growth rate. Thus, in this study, the lack of a decrease in fibroblast proliferation may reflect the initiation of the recovery phase. Although mean doubling times in BRF tend to be longer (but no $>12 \%$ above NRF mean values), these increases were not statistically significant, nor were they consistently seen from one preparation to another. Similarly, in their study, Absher et al. (24) failed to demonstrate statistically significant differences in the number of cells obtained at stationary phase $(P=0.097)$ as well as in interdivision times as determined by time-lapse cinematography. It is thus also possible that small differences are being masked by the variability in the cell preparations. Direct in vivo measurements of lung fibroblast growth rate may be necessary to define the cause for this apparent discrepancy. An actual permanent reduction in fibroblast growth rate would be inconsistent with the morphology of fibrotic lesions wherein increased fibroblast numbers are the rule, unless the increased numbers are solely due to recruitment (chemotactic attraction) of cells from neighboring areas.

Despite this apparent lack of difference in growth rates in this study, lungs from bleomycin-treated animals, however, are digested more efficiently and to a greater extent, resulting in a higher initial yield of cells, than those from control animals. This is probably a reflection of the increased cellularity of bleomycin lungs secondary to inflammation and increased connective tissue cell numbers. The newly synthesized collagen also contained a lower relative content of type III vs. type I collagen, consistent with the composition of fibrotic lesions $(19,20,22)$ and of normal isolated fibroblasts treated with bleomycin in vitro (7). Collagenase and protease (data not shown) production and secretion were also unaffected by in vivo bleomycin treatment.

The mechanism of this alteration in lung fibroblast collagen production can only be speculated upon at this time. The simplistic approach would be to regard this as the result of direct bleomycin effects on the lung fibroblasts in vivo, mimicking the well-described in vitro effects of this drug on isolated fibroblasts $(7,8)$. However this appears unlikely for the following reasons: 1) very little bleomycin is in the lung 7-14 d after treatment (25), and in one study $<25 \%$ of peak levels remained in the lung $24 \mathrm{~h}$ after treatment (26). BRF was isolated $14 \mathrm{~d}$ after treatment, thus very little bleomycin should remain during the isolation procedure. 2) Furthermore, BRF could be further stimulated by in vitro bleomycin treatment to an extent equal to that of NRF, suggesting that BRF have retained the responsiveness of normal fibroblasts to this drug. In in vitro studies we have found that rechallenge with bleomycin is toxic to fibroblasts and severely impairs their growth rate (data not shown). BRF, on the other hand, showed none of these effects (i.e., it propagated and subcultured normally). Thus there are distinct differences between cells treated with bleomycin in vitro and those derived from bleomycin-treated animals (i.e., BRF). These differences provide further support for the conclusion that increased collagen production by BRF is not due to direct bleomycin effects on lung fibroblasts in vivo (i.e., before their isolation).

Despite these observations, however, we cannot rule out an in vivo mediated but direct irreversible effect on these fibroblasts, resulting in homogeneous alteration of all cell 
populations or selection of a more active (in terms of collagen synthesis) subpopulation. The latter possibility is supported by data showing the heterogeneity of fibroblast populations (27).

Alternative mechanisms would invoke indirect bleomycin effects, but ultimately should result in the same outcome as described in the two possible schemes outlined above. The irreversible alterations of BRF may be mediated by factors produced by cells of the immune system (e.g., alveolar macrophage and lymphocytes) upon stimulation by the bleomycininduced process. These cells are known to be sources of relatively well-defined mediators capable of regulating fibroblast growth and metabolism (28-30). Furthermore, mediators produced by mononuclear cells can irreversibly alter certain fibroblast functions (31). Finally, bleomycin effects on other cells (e.g., endothelial, epithelial, etc.) could also result in release of factors, with similar consequences on fibroblasts. Although these alterations appear irreversible under in vitro culture conditions, the bleomycin-induced increased rate of lung collagen synthesis in vivo, on the other hand, is finite $(10,13)$. Since BRF was obtained at $14 \mathrm{~d}$ after bleomycin instillation, which is the period of increased lung collagen synthesis, it may be that inhibitory factors are required to down-regulate these BRF in vivo to return to the quiescent state seen at periods $\geq 8$ wk after bleomycin instillation. This would imply that the irreversibility is applicable only to the in vitro status of these BRF.

\section{Acknowledgment}

We thank Bristol Labs for the gift of Blenoxane. We would like to acknowledge the excellent technical assistance of Bridget McGarry and Patty Perrone and the secretarial assistance of Jeny Breakstone.

This work was supported by National Institutes of Health grants HL28737 and HL31963 and a grant-in-aid from the American Heart Association and its Michigan affiliate.

\section{References}

1. Ishizaka, M. H., T. Takayama, T. Takeuchi, and H. Umezawa. 1967. Activity and toxicity of bleomycin. J. Antibiot. (Tokyo) Ser. A. 20:15-24.

2. Delena, M., A. Guzzon, S. Monfardini, and G. Bonnadonna. 1972. Clinical, radiological and histopathological studies on pulmonary toxicity induced by treatment with bleomycin. Cancer Chemother. Rep. 56:343-356.

3. Thrall, R. S., S. H. Phan, J. R. McCormick, and P. A. Ward. 1981. The development of bleomycin-induced pulmonary fibrosis in neutrophil-depleted and complement-depleted rats. Am. J. Pathol. 105: 76-81.

4. Schrier, D. J., S. H. Phan, and B. M. McGarry. 1983. The effects of the nude (nu/nu) mutation on bleomycin-induced pulmonary fibrosis: a biochemical evaluation. Am. Rev. Respir. Dis. 127:614-617.

5. Neilson, E. G., S. A. Jimenez, and S. M. Phillips. 1980. Cell mediated immunity in interstitial nephritis. III. T-lymphocyte mediated fibroblast proliferation and collagen synthesis: an immune mechanism for renal fibrogenesis. J. Immunol. 125:1708-1714.

6. Keogh, B. A., and R. G. Crystal. 1982. Alveolitis: the key to the interstitial lung disorders. Thorax. 37:1-10.

7. Clark, J. G., B. C. Starcher, and J. Uitto. 1980. Bleomycininduced synthesis of type I procollagen by human lung and skin fibroblasts in culture. Biochim. Biophys. Acta. 631:359-370.

8. Sterling, K. M., Jr., M. J. Harris, J. J. Mitchell, and K. R. Cutroneo. 1983. Bleomycin treatment of chick fibroblasts causes an increase of polysomal type I procollagen mRNAs. J. Biol. Chem. 258: 14438-14444.

9. Ichihashi, M., H. Shinkai, M. Takei, and S. Sano. 1973. Analysis of the mechanism of bleomycin induced cutaneous fibrosis in mice. $J$. Antibiot. (Tokyo). 26:238-242.

10. Phan, S. H., R. S. Thrall, and C. Williams. 1981. Bleomycininduced pulmonary fibrosis: effects of steroid on lung collagen metabolism. Am. Rev. Respir. Dis. 124:428-434.

11. Peterkovsky, B., and R. Diegelmann. 1971. Use of a mixture of proteinase free collagenases for the specific assay of radioactive collagen in the presence of other proteins. Biochemistry. 10:988-994.

12. Juva, K., and D. J. Prockop. 1966. Modified procedure for the assay of ${ }^{3} \mathrm{H}$ - or ${ }^{14} \mathrm{C}$-labelled hydroxyproline. Anal. Biochem. 15:77-83.

13. Phan, S. H., R. S. Thrall, and P. A. Ward. 1980. Bleomycininduced pulmonary fibrosis in rats: biochemical demonstration of increased rate of collagen synthesis. Am. Rev. Respir. Dis. 121:501506.

14. Sykes, B. C. 1976. The separation of two soft-tissue collagens by covalent chromatography. FEBS (Fed. Eur. Biochem. Soc.) Lett. 61:180-185.

15. Neville, D. M. 1971. Molecular weight determination of protein dodecyl sulfate complexes by gel electrophoresis in a discontinuous buffer system. J. Biol. Chem. 246:6328-6334.

16. Phan, S. H., and P. A. Ward. 1979. Generation of biologic activity from the purified $\alpha$-chain of C5. J. Immunol. 123:2735-2740.

17. Gabbiani, G., B. J. Hirschel, G. B. Ryan, P. R. Statkov, and G. Majno. 1972. Granulation tissue as a contractile organ. A study of structure and function. J. Exp. Med. 135:719-734.

18. Seyer, J. M., E. T. Hutcheson, and A. H. Kang. 1976. Collagen polymorphism in idiopathic chronic pulmonary fibrosis. J. Clin. Invest. 57:1498-1507.

19. Madri, J. A., and H. Furthmayr. 1980. Collagen polymorphism in the lung: an immunohistochemical study of pulmonary fibrosis. Hum. Pathol. 11:353-366.

20. Bateman, E., M. Turner-Warwick, and B. C. Adelman-Grill. 1981. Immunohistochemical study of collagen types in human foetal lung and fibrotic lung disease. Thorax. 36:645-653.

21. Clore, J. N., I. K. Cohen, and R. F. Diegelmann. 1979. Quantitation of collagen types I and III during wound healing in rat skin. Proc. Soc. Exp. Biol. Med. 161:337-340.

22. Reiser, K. M., and J. A. Last. 1981. Pulmonary fibrosis in experimental acute respiratory disease. Am. Rev. Respir. Dis. 123:5863.

23. Phan, S. H., and R. S. Thrall. 1982. Inhibition of bleomycininduced pulmonary fibrosis by cobra venom factor. Am. J. Pathol. 107:25-28.

24. Absher, M., J. Hildebran, L. Trombley, J. Woodcock-Mitchell, and J. Marsch. 1984. Characteristics of cultured lung fibroblasts from bleomycin-treated rats. Am. Rev. Respir. Dis. 129:125-129.

25. Adamson, I. Y. R., and D. H. Bowden. 1979. Bleomycininduced injury and metaplasia of alveolar type 2 cells. Am. J. Pathol. 96:531-544.

26. Lazo, J. S., and E. T. Pham. 1984. Pulmonary fate of $\left({ }^{3} \mathrm{H}\right)$ bleomycin $\mathrm{A}_{2}$ in mice. J. Pharmacol. Exp. Ther. In press.

27. Brody, J. S., and N. B. Kaplan. 1983. Proliferation of alveolar interstitial cells during postuatal lung growth: evidence for two distinct populations of pulmonary fibroblasts. Am. Rev. Respir. Dis. 127:763770.

28. Wahl, S. M., L. M. Wahl, and J. B. McCarthy. 1978. Lymphocyte-mediated activation of fibroblast proliferation and collagen production. J. Immunol. 121:942-946.

29. Bitterman, P. B., S. I. Rennard, G. W. Hunninghake, and R. G. Crystal. 1982. Human alveolar macrophage growth factor for fibroblasts. Regulation and partial characterization. J. Clin. Invest. 70: 806-822.

30. Postlethwaite, A. E., and A. H. Kang. 1983. Induction of fibroblast proliferation by human mononuclear leukocyte-derived proteins. Arthritis Rheum. 26:22-27.

31. Korn, J. H. 1983. Fibroblast prostaglandin $E_{2}$ synthesis: persistence of an abnormal phenotype after short-term exposure to mononuclear cell products. J. Clin. Invest. 71:1240-1246. 